\title{
Using Oral Quizzes in an Engineering Mechanics Course
}

\author{
Jamie Douglas, Ph.D. \\ Assistant Professor of Engineering \\ University of Wisconsin, Fox Valley \\ jamie.douglas@uwc.edu \\ Rachel Knighten \\ Associate Professor of Spanish \\ Chair, Department of World Languages \\ University of Wisconsin, Fox Valley \\ rachel.knighten@uwc.edu
}

\begin{abstract}
Engineers are required to be competent technical experts and also effective communicators. This paper describes the development of a rubric for oral quizzes in engineering mechanics courses. The rubric was developed collaboratively with the engineering and world languages departments, and tested in a single section of Engineering Mechanics: Statics in the spring of 2014. The goals of the oral quizzes were to increase students' comfort with explaining a solution method, competency using appropriate technical language, and ability to organize the problem solving method. Oral quizzes (versus pen-and-paper or online quizzes) also provide the instructor with the ability to immediately prompt a student who might be unsure of how to proceed with a problem and identify misconceptions or areas of weakness for specific students. The rubrics provide a means to measure the student performance in each of the goal areas: technical language, organization, content, clarity, and attitude. This paper includes anecdotal evidence from students on their attitudes about the oral quizzes, and compares performance on oral quizzes with the same questions given in a traditional format.
\end{abstract}

\section{Introduction}

This paper begins with background information and a brief review as to why oral quizzes were implemented in the engineering mechanics course. Student and instructor feedback are then presented. Finally, some conclusions and future work are discussed.

The University of Wisconsin-Fox Valley is one of 13 two-year campuses that make up the University of Wisconsin Colleges (UWC). The UWC mission is access to higher education and to prepare students for success at the baccalaureate level of education. The UWC offers the first two years of general education as well as calculus, chemistry, physics, introductory engineering courses, and the engineering mechanics courses for engineering majors.

The motivation to pilot oral quizzes with this class was two-fold. The primary reason oral quizzes were explored was an increased need for technical communication skills among engineering graduates. Often teaching communication to engineers focuses on writing skills ${ }^{2}$, but other forms of communication can be equally important. ${ }^{4}$ The secondary motivation was to use the quizzes as an opportunity to assess students as well as prepare them for traditional pen-andpaper exams. Anecdotal evidence in pervious semesters pointed to student's increased use of 
illegally published homework solution guides online. As instructors, one possible means to discourage the use of solution manuals is to decrease the proportion of the grade that is based on the homework assignments. This leads to a much larger percentage of a student's assessment being based on traditional exams. The instructors have found that pen-and-paper exams alone do not capture a full picture of a student's understanding of the material. Oral exams offer opportunity to assess student's understanding of the material in an alternative setting.

Many engineering faculty do not have experience using oral assessments in classes as it's not a traditional means of assessing engineering content. However, world language classes often have oral assessments to evaluate a student's verbal proficiency with a second language. The pilot rubric for the engineering quizzes was created in consultation with a world languages department faculty member who had extensive experience with oral exams.

This pilot study on oral quizzes was administered to a small (15 student) class of engineering statics students at the University of Wisconsin, Fox Valley.

\section{Literature Review}

The literature addressed the logistics of administering oral assessments, pointing to the efficiency of evaluating student work while providing timely and individualized feedback; the role of bias in an examination mode that can be more subjective than a written exam and the importance of ensuring reliable evaluation criteria; and the value of fostering and assessing oral communication skills. Studies on the use of oral assessments in science and engineering classes focus on two separate but potentially related aspects: 1 ) the use of oral assessments to foster and evaluate learning, and 2) the use of oral assessments to streamline the examination process for the instructor. Finally, the use of oral assessment addresses the value of developing students' communication skills.

Evaluating student learning is a time-consuming and complex process. Designing exams that provide opportunities for students to demonstrate what they know, identify students who have not learned the course content, and can be graded efficiently so as to provide timely feedback (or meet university deadlines, as in the case of final exams), is an ever-present challenge. Additionally, instructors must take precautions to discourage cheating. Jensen notes that "The result is therefore that most engineering courses are assessed by written exam papers that mainly require mathematical answering. The descriptive questions that could test the student's deeper understanding of the subject matter are often omitted purely because it is so labour intense to assess these questions."1 Oral assessments are presented as an alternative to written assessments that permit the instructor to evaluate students' conceptual understanding of the course content. As Sayre observes "Within longer problems (as scaffolded in an oral exam), an examiner can also easily assess the connections between the student's physical intuition and mathematical formalism, and determine the differences between memorized steps and conceptual understanding by asking the student why he makes each choice..$^{5}$ The literature identifies oral assessments as an opportunity to engage students in an authentic evaluation of their understanding of the course content. In addition, strong communication skills are highly valued in the workplace yet rarely explicitly addressed in introductory engineering courses. According to Huxham et al., oral assessments demonstrate the importance of oral 
communication and provide opportunities to practice and refine communication in this modality. ${ }^{3}$

Studies on the use of oral assessment also highlight practical considerations in the administration of this type of exam. Oral exams are necessarily conducted individually with students, however, researchers pointed out that in the case of smaller classes, the amount of time necessary to meet with students individually is comparable to the amount of time necessary to compose and grade a written exam. ${ }^{1,5}$ The literature on the use of oral assessment suggests that this mode can foster deeper learning as well as be an effective strategy for evaluating student learning.

\section{Implementation}

A total of four oral quizzes, one per "unit," were given over the course of a 15-week semester. Quizzes were scheduled approximately one week prior to the unit written exam. Students selected an individual 15 minute timeslot outside of class time to take the quiz. Quiz questions were drawn from a pool of practice problems for the Fundamentals of Engineering Exam. Half as many problems were created as students in the class, so that each quiz problem was solved by two students. The problems were numbered and assigned randomly to students by asking them to pick a number from the available pool without being able to preview any of the problems.

Students were given the problem and approximately 1-2 minutes to interpret and develop a strategy to solve it. Each student was also asked if he/she understood the problem or had any questions before beginning to work. Students were encouraged to talk during the entire quiz period and explain every step of what they were doing. For most engineering statics problems, this began with a list of known variables and a free body diagram. Students then set up equations and calculated the answer.

The instructor's role in the problem solving process varied widely depending on the student. Students who were confident and correct in their approach could work through the problem with very little interaction from the instructor. Many students with correct approaches often did look for reassurance from the instructor, which could be anything from a nod to verbal affirmation that their strategy was good.

If a student made a basic mistake, such as a plus/minus or sine/cosine error; the instructor would wait a few moments to see if the student was able to catch their own mistake. This would often happen naturally when the student attempted to use the incorrect value in the next equation. Students who did not catch their own errors were stopped by the instructor and prompted to look at either the value or the equation again. If a generic prompt was not sufficient for the student to find their own mistake, then the instructor would correct the mistake for the student and the student would continue.

Students were also free to ask questions in the middle of a quiz, and some took advantage of that option to ask a general conceptual question. For example, a student might create a crosssection and then say, "I've always drawn the forces in this direction, but I've never understood why. Could you explain it one more time?” 
Rarely, a student would not be able to begin the problem or would not be able to solve the problem with only minimal prompting. In those cases, the quiz would become a tutorial with the instructor showing the student how to set up and solve the problem.

Once the student had completed the problem, there were two follow-up questions. The first was designed to measure a student's conceptual understanding over their numerical ("plug and chug") abilities. An example follow-up question would be: "You solved the problem for the forces at A; what would be different if you did the same thing for B?"

At that point, the quiz was scored and the scores shared with the students. The second postquiz question was always whether or not the student had any other questions they would like to ask about the course material or the upcoming exam. Quizzes were specifically scored before this follow-up question so that a student would not fear that asking for clarification or having questions about the material might affect their quiz grade

Student performance was assessed using a rubric, which was shared with the students prior to the quiz. The rubric was standard for all quizzes for all units. Outlined below are the five areas of assessment on the rubric and the main goal being assessed in that category:

Vocabulary / Terminology: evaluates the student's ability to use proper terms and vocabulary that was relevant to the course and the problem.

Content: evaluates the student's ability to draw correct figures and select correct equations

Solution: addresses the mathematical aspects of the problem and the student's ability to use the numerical information correctly.

Organization/Command of Problem: assesses the student's understanding of the problem and ability to explain the meaning of the answer.

Effort and Motivation: gauges the student's communication style and engagement in the quiz process.

A sample rubric is provided at the end of this paper. The authors would like to note that rubrics for verbal language skills focus primarily on how a speaker is able to say words and use vocabulary in a second language. The rubric for engineering skills needed to fit the technical language as well as specific engineering content and mathematical skills. The rubric was also designed to be flexible enough that it could be used regardless of the subject matter or chapters covered on the quiz.

\section{Observations and Results}

Students were surveyed at the end of the semester about their level of comfort with the oral quizzes and how having oral quizzes helped in specific areas of their learning. Thirteen of 15 students in the course completed the survey. 
Only a single student indicated that he/she liked the idea of oral quizzes at the beginning of the semester. However, eighty-five percent of students indicated a greater level of comfort with the oral quizzes at the end of the semester than at the beginning of the semester and only a single student reported that he/she still disliked the quizzes at the end of the semester.

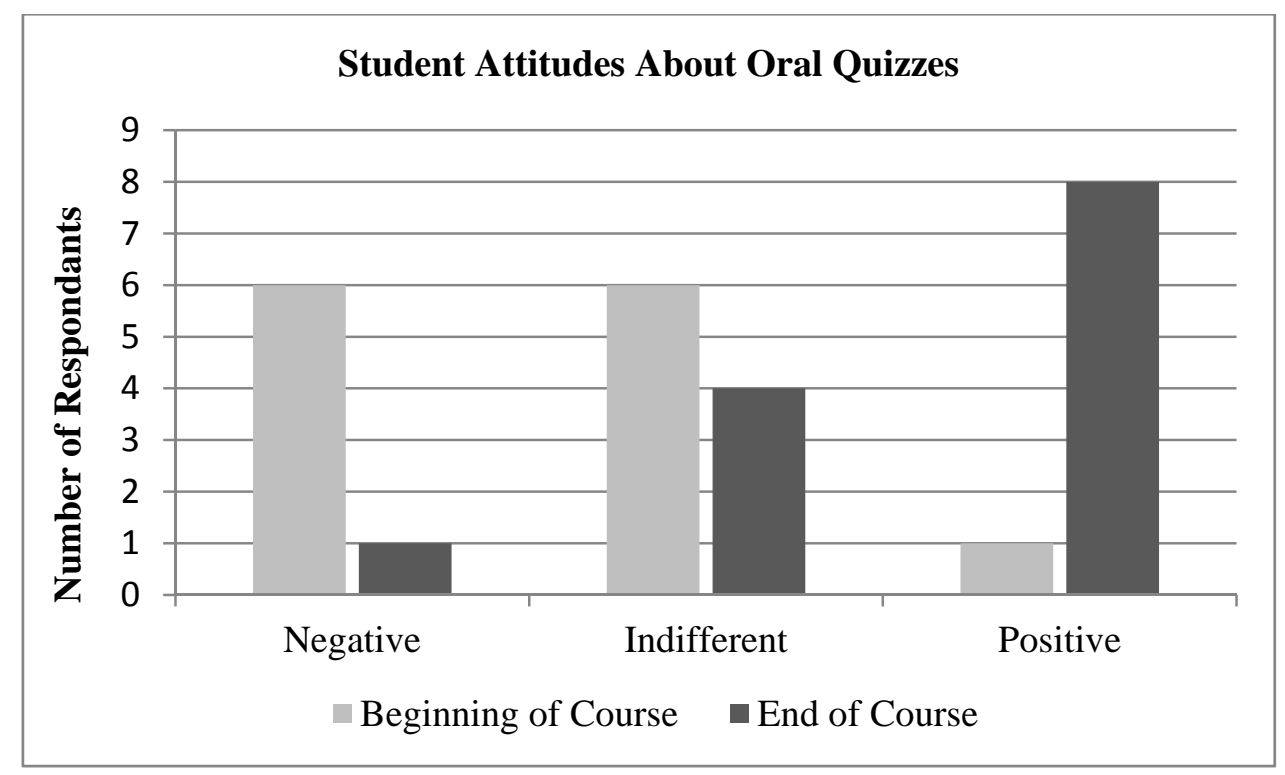

Many students (77\%) opted to share additional comments on the surveys. A common recurring theme in the open-ended comments related to the student's appreciation of feedback during a test.

"It allowed the student to show where they understood material and where there was confusion."

"This was an excellent way to test my abilities as well as receive immediate instruction if a mistake was made throughout the problem. I felt much more motivated to succeed."

"I mostly liked the quizzes because if I got confused you showed the right way to go and I didn't get frustrated \& I liked the time to ask questions about anything I was unsure about, otherwise I probably never would have asked."

"Helped me know what had (sic) to work on \& liked that I could ask a question in case I got stuck because losing a point or two is better than getting the entire problem wrong"

\section{Student Feedback on Quiz Goals}

The primary reasons for introducing oral quizzes in this engineering class were to improve student's ability to explain technical information and to identify any problems in students' understanding prior to the higher-stakes exams. To determine if the quizzes were meeting these goals, students were surveyed on how the quizzes helped them in specific areas. 


\begin{tabular}{|l|l|l|l|}
\hline Did the oral quizzes help you.... & Yes & Unsure & No \\
\hline ... explain your approach & 11 & 0 & 2 \\
\hline ... work under pressure & 12 & 0 & 1 \\
\hline .. identify a problem or error you had with a problem & 8 & 5 & 0 \\
\hline ... identify a mistake that you make multiple times & 8 & 2 & 3 \\
\hline .. set-up problems & 9 & 1 & 3 \\
\hline .. use correct terms and language to describe problems & 12 & 0 & 1 \\
\hline ... improve technical communication skills & 9 & 3 & 1 \\
\hline ... prepare for exams & 11 & 1 & 1 \\
\hline
\end{tabular}

Students expressed gains in all areas. The highest positive impacts for students in technical fluency were in explaining an approach and using correct terms and language. The highest positive impacts for student classroom skills were working under pressure and preparing for exams.

Average quiz scores were higher than average exam scores for the same unit by 6-11 points. Since quizzes took place approximately a week before the exam, less material was covered on the quizzes compared with the exams. The quiz problems were also slightly easier than the exam problems due to the limited time to complete the quiz.

The average score of all quizzes for all students was $88.9 \%$. The same pool of questions was used in two other sections of Engineering Statics, one face-to-face course taught in the previous semester and one online course. In aggregate, the oral quizzes resulted in high average grades than the same problems given as pen-and-paper quizzes in a face-to-face course (82.4\%) and as multiple-choice, timed quizzes in an online course $(86.1 \%)$. The class sizes $(15,11,12)$ are too small to analyze the specific quizzes or data from subtopics in greater detail.

\section{Conclusions}

The purpose of this project was to use oral quizzes to increase student competence with technical communication and create a formative assessment that would enable students to better prepare for written exams.

The outcome of the initial pilot was successful, with students reporting positive gains in both technical communication and content mastery. Students appreciated the opportunity to get feedback during the quiz period and generally noted that they preferred to lose a point or two for a minor mistake if it allowed them to successfully complete the problem. Students also noted that they appreciated the opportunity to ask questions during and following the quiz.

In this small pilot group, the oral assessment was likely more efficient than a traditional assessment when weighed against the personal nature of the feedback, the timeliness of the feedback, and the increased performance on the assessment. The challenges to implementation of oral quizzes on a larger scale are the time involved in developing additional problems and physically administering the quizzes. 
Future work on this project includes work to address the ongoing challenges. Additionally, the literature notes that oral quizzes and alternative assessments have specific advantages for underrepresented groups of students. The authors would like to explore this further, but do not have sufficient data to look at those variables with this limited pilot study.

\section{Bibliography}

1. Bech Jensen, Bogi. "Oral Assessment in Engineering Education," International Journal of Electrical Engineering Education, 2010.

2. $\quad$ Donnell, J.A., B.M. Aller, M. Alley, A.A. Kendrowicz, "Why Industry Says That Engineering Graduates Have Poor Communication Skills: What the Literature Says,” American Society of Engineering Education, 2011.

3. Huxham, M., Campbell, F., Westwood, J. "Oral versus Written Assessments: A Test of Student Performance and Attitudes," Assessment and Evaluation in Higher Education, 2012.

4. Riemar, M.J., "Communication Skills for the $21^{\text {st }}$ Century Engineer," Global Journal of Engineering Education, 2007.

5. $\quad$ Sayre, E. "Oral Exams as a Tool for Teaching and Assessment," Teaching Science, 2014. 
Quiz Rubric

\begin{tabular}{|c|c|c|c|c|c|c|}
\hline & 1 & 2 & 3 & 4 & 5 & Multiplier \\
\hline $\begin{array}{l}\text { Vocabulary / } \\
\text { Terminology }\end{array}$ & $\begin{array}{l}\text { Unable to use proper } \\
\text { technical terminology to } \\
\text { discuss problem and } \\
\text { solution }\end{array}$ & $\begin{array}{l}\text { Unsure of proper } \\
\text { terminology }\end{array}$ & $\begin{array}{l}\text { Student needs to be } \\
\text { prompted to clarify, is } \\
\text { unaware of specialized } \\
\text { technical terms }\end{array}$ & $\begin{array}{l}\text { Generally uses proper } \\
\text { terminology to describe } \\
\text { problem, may need some } \\
\text { support but generally } \\
\text { knows proper technical } \\
\text { terms }\end{array}$ & $\begin{array}{l}\text { Uses proper terminology } \\
\text { to describe problem, } \\
\text { includes specialized } \\
\text { vocabulary specifically } \\
\text { related to topic }\end{array}$ & 0.3 \\
\hline Content & $\begin{array}{l}\text { Unsure of how to work } \\
\text { problem. Unable to draw } \\
\text { and label correct figures. } \\
\text { Unable to determine or } \\
\text { recall equations. }\end{array}$ & $\begin{array}{l}\text { Frequent prompting to } \\
\text { draw figures and/or help } \\
\text { with determining which } \\
\text { equations to use to solve } \\
\text { problem }\end{array}$ & $\begin{array}{l}\text { Needs prompting to } \\
\text { draw or label correct } \\
\text { figures and/or arrive at } \\
\text { the proper equations. }\end{array}$ & $\begin{array}{l}\text { Draws and labels correct } \\
\text { figures and uses correct } \\
\text { equations, uses } \\
\text { equations out of order or } \\
\text { in an illogical sequence }\end{array}$ & $\begin{array}{l}\text { Draws correct figures, } \\
\text { uses correct equations in } \\
\text { logical sequence }\end{array}$ & 1.5 \\
\hline Solution & $\begin{array}{l}\text { Needs frequent } \\
\text { prompting to arrive at } \\
\text { correct answer with } \\
\text { correct number of } \\
\text { significant digits and } \\
\text { units. Makes multiple } \\
\text { sign errors or sine/cosine } \\
\text { errors. }\end{array}$ & $\begin{array}{l}\text { Needs frequent } \\
\text { prompting to arrive at } \\
\text { correct answer with } \\
\text { correct number of } \\
\text { significant digits and } \\
\text { units. Makes sign error } \\
\text { or sine/cosine errors. }\end{array}$ & $\begin{array}{l}\text { Needs some prompting } \\
\text { to arrive at correct } \\
\text { answer with correct } \\
\text { number of significant } \\
\text { digits and units. May } \\
\text { make sign error or } \\
\text { sine/cosine errors. }\end{array}$ & $\begin{array}{l}\text { Arrives at correct answer } \\
\text { with correct number of } \\
\text { significant digits and } \\
\text { units with minimal } \\
\text { prompting. }\end{array}$ & $\begin{array}{l}\text { Arrives at correct answer } \\
\text { with correct number of } \\
\text { significant digits and } \\
\text { units. }\end{array}$ & 1.4 \\
\hline $\begin{array}{l}\text { Organization / } \\
\text { Command of } \\
\text { Problem }\end{array}$ & $\begin{array}{l}\text { Student is unable to } \\
\text { explain or understand } \\
\text { the problem-solving } \\
\text { method or the meaning } \\
\text { of the problem's answer. }\end{array}$ & $\begin{array}{l}\text { Student cannot explain } \\
\text { problem solving-process } \\
\text { clearly, needs prompting } \\
\text { to understand the } \\
\text { process and/or meaning } \\
\text { of the problem's answer. }\end{array}$ & $\begin{array}{l}\text { Student cannot explain } \\
\text { problem solving-process } \\
\text { clearly, or appears to rely } \\
\text { on memorization of } \\
\text { problem solving methods } \\
\text { to explain. }\end{array}$ & $\begin{array}{l}\text { Student provides some } \\
\text { insight into problem } \\
\text { solving-process and can } \\
\text { explain significance of } \\
\text { answer. }\end{array}$ & $\begin{array}{l}\text { Student can explain } \\
\text { problem-solving process } \\
\text { and explain the meaning } \\
\text { of the answer. }\end{array}$ & 0.5 \\
\hline $\begin{array}{l}\text { Effort \& } \\
\text { Motivation }\end{array}$ & $\begin{array}{l}\text { Student fails to } \\
\text { communicate beyond } \\
\text { bare minimum. }\end{array}$ & $\begin{array}{l}\text { Student struggles to } \\
\text { communicate, relies on } \\
\text { instructor to fill-in gaps. }\end{array}$ & $\begin{array}{l}\text { Student needs } \\
\text { assistance. Answers } \\
\text { questions willingly; } \\
\text { elaborates with } \\
\text { prompting. }\end{array}$ & $\begin{array}{l}\text { Student participates } \\
\text { willingly in the interview, } \\
\text { may need some } \\
\text { guidance. Elaborates } \\
\text { with little or no } \\
\text { prompting. }\end{array}$ & $\begin{array}{l}\text { Student engages listener } \\
\text { and shows initiative } \\
\text { during the interview. }\end{array}$ & 0.3 \\
\hline
\end{tabular}

Quiz Grade: 